\title{
A Terapia Ocupacional na sociedade capitalista e sua inserção profissional nas políticas sociais no Brasil ${ }^{1}$
}

\author{
Waldez Cavalcante Bezerra ${ }^{a}$, Rosa Lúcia Prédes Trindade ${ }^{b}$ \\ aTerapeuta ocupacional, Mestre em Serviço Social pela UFAL, Integrante do Grupo de Pesquisa "Serviço Social, \\ Trabalho e Políticas Sociais" da UFAL e do Grupo de Pesquisa "Saúde Mental e Saúde Coletiva" da UNCISAL, \\ Docente do curso de Terapia Ocupacional, Universidade Estadual de Ciências da Saúde de Alagoas, \\ UNCISAL, Maceió, Alagoas, Brasil

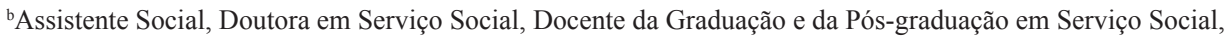 \\ Líder do Grupo de Pesquisa "Serviço Social, Trabalho e Políticas Sociais" da UFAL, Professora Adjunta, \\ Faculdade de Serviço Social, Universidade Federal de Alagoas - UFAL, Maceió, Alagoas, Brasil
}

\begin{abstract}
Resumo: Apresenta-se uma reflexão sobre a inserção do terapeuta ocupacional na divisão social do trabalho, enquanto profissional assalariado, e a relação entre ele e o Estado capitalista, buscando refletir sobre o processo de constituição e desenvolvimento da Terapia Ocupacional, enquanto profissão, no contexto de transformações no trabalho e nas políticas sociais. Realizaram-se pesquisas bibliográfica e documental, tomando como base os referenciais marxiano e marxista, com o intuito de refletir sobre o objeto em questão, numa perspectiva ontológica. Identificou-se que a inserção da Terapia Ocupacional na divisão social do trabalho configura-se como resultado de um processo histórico, dependente das formas de intervenção estatal sobre as expressões da questão social, da configuração da luta de classes e da conformação das políticas sociais do Estado no contexto do capitalismo monopolista. No cenário brasileiro, a Terapia Ocupacional vem passando por um processo de reconfiguração profissional, marcado pela incorporação de novas atribuições profissionais e novas áreas de atuação profissional decorrentes das transformações sociais brasileiras.
\end{abstract}

Palavras-chave: Capitalismo, Trabalho, Estado, Política social, Terapia Ocupacional.

\section{Occupational Therapy in capitalist society and its professional insertion in the Brazilian Social Policies}

\begin{abstract}
In this study, we present a reflection on the insertion of occupational therapists in the work social division, as professional employees, and the relation between this and the capitalist state, aiming to reflect on the process of formation and development of Occupational Therapy as a profession, within the context of changes in work practices and social policies. Documental and literature searches were carried out using a methodological approach based the Marxian and Marxist referential, aiming to reflect upon the subject matter under an ontological perspective. It was possible to identify that the insertion of Occupational Therapy, within the work social division, is configured as a result of a historical process dependent on forms of state intervention on the expressions of social issues and configuration of class struggle and on the conformation of state social policies in the context of monopolist capitalism. Within the Brazilian context, Occupational Therapy has undergone a process of professional reconfiguration marked by the incorporation of new professional attributions and areas, as a result of societal changes in the country.
\end{abstract}

Keywords: Capitalism, Work, State, Social Policy, Occupational Therapy.

\footnotetext{
Autor para correspondência: Waldez Cavalcante Bezerra, Universidade Estadual de Ciências da Saúde de Alagoas. Curso de Terapia Ocupacional, Rua Jorge de Lima, 113, Trapiche da Barra, CEP 57010-300, Maceió, Al. e-mail: waldezto@ yahoo.com.br Recebido em 19/12/2011; Revisão em 1/6/2012; Aceito em 11/6/2012.
} 


\section{Introdução}

$\mathrm{O}$ artigo aqui apresentado tem como objeto de estudo a profissão de terapeuta ocupacional, em suas relações com o trabalho e as políticas sociais públicas. Com o objetivo de analisar a inserção do terapeuta ocupacional na divisão social do trabalho enquanto profissional assalariado e a relação entre ele e o Estado capitalista, buscamos refletir sobre o processo de constituição e desenvolvimento da Terapia Ocupacional no contexto de transformaçóes no trabalho e nas políticas sociais.

Para o desenvolvimento da investigação realizamos pesquisas bibliográfica e documental, tomando como base os referenciais marxiano e marxista, com o intuito de refletir sobre o objeto em questão numa perspectiva ontológica. Compreendemos o método como uma forma de apreensão do real baseada em uma concepção de mundo, na qual o pesquisador se apoia para investigar determinada realidade social. Assim, percorrer as múltiplas determinações do objeto de estudo é o núcleo norteador do pensamento marxiano. Pois tudo o que aparece e se move na reflexão - construção do conhecimento - é a substância e a lógica do objeto analisado, que é reproduzido pelo cérebro em sua gênese e necessidade, historicamente engendradas e desenvolvidas (LARA, 2007, p. 79).

Para atender esse pressuposto teórico-metodológico, o pesquisador parte da imediaticidade (objeto de estudo) - que é síntese das determinações sociais, políticas, econômicas, ideológicas - para, através de mediaçôes, aproximar-se de uma compreensão que contemple as múltiplas determinaçóes do objeto, na sua totalidade (LARA, 2007, p. 79).

Esse método de apreensão da realidade social tem como premissa a construção de um saber que pôe em primeiro momento as condiçóes sociais reais do homem e suas formas de existência, uma vez que, no entender de Marx (1983, p. 24),

[...] o modo de produção de vida material condiciona o desenvolvimento da vida social, política e intelectual em geral. Não é a consciência dos homens que determina o seu ser, é o seu ser social que, inversamente, determina a sua consciência.

Desse modo, é denominada ontológica uma perspectiva teórico-metodológica que busca nas obras de Marx (referencial marxiano) e de seus principais seguidores (referencial marxista) os fundamentos essenciais para análise e apreensão do objeto em estudo.
Nesse sentido, pensamos que a profissão terapia ocupacional, aqui tomada como objeto de estudo, é consequência de uma realidade concreta que é determinada socialmente, ou seja, estabelece-se numa sociedade que se produz e reproduz por meio de suas contradiçôes inconciliáveis. Além disto, adotar uma perspectiva teórico-metodológica que reconhece a realidade social como ponto de partida das análises científicas e da produção do conhecimento aproxima-nos de respostas concretas diante dessa mesma realidade.

$\mathrm{Na}$ pesquisa bibliográfica recorremos às obras de Marx e de seus seguidores, como Engels e Lukács, e a autores da Terapia Ocupacional que se preocuparam em estudar a gênese e desenvolvimento histórico da profissão ${ }^{2}$. A técnica utilizada para tratamento do material bibliográfico e a sua organização seguiu as proposiçôes de Lima e Mioto (2007, p. 41): leitura de reconhecimento do material bibliográfico, leitura exploratória, leitura seletiva, leitura reflexiva e leitura interpretativa. $\mathrm{Na}$ pesquisa documental recorremos ao estudo de material documental escrito, que não sofreu nenhum tipo de tratamento analítico prévio, ou seja, tratam-se de fontes primárias, de acordo com Sá-Silva, Almeida e Guindani (2009, p. 6), mais especificamente, as resoluções e leis do Conselho Federal de Fisioterapia e Terapia Ocupacional (Coffito) e documentos governamentais.

Com esse aporte teórico-metodológico, o estudo está baseado no princípio de que a profissão de terapeuta ocupacional - mas não somente ela - apresenta, além de uma dimensão políticoideológica, uma funcionalidade econômica para o capital, traço esse inerente ao exercício profissional, devido à própria natureza da profissão e à sua forma de inserção na divisão social do trabalho capitalista. Sendo assim, a profissão participa do processo de produção e reprodução das relações sociais capitalistas, na medida em que atua, através de políticas e serviços sociais, sobre as expressões da exploração da força de trabalho pelo capital, seja no seu aspecto biológico mais imediato ou náo. É, portanto, seguindo essa linha de pensamento que conduziremos a reflexão que se segue, com intuito de demonstrar as particularidades do processo de constituição e desenvolvimento da profissão numa perspectiva ontológica marxiana.

É válido ressaltar que, no interior da Terapia Ocupacional, vários foram os estudos que se debruçaram sobre os fundamentos históricos da profissão. Do mesmo modo, diversos são os recortes metodológicos e perspectivas teóricas utilizados pelos autores para analisar a profissão numa perspectiva histórica; contudo, poucos são aqueles que, nesse 
processo de investigação, ousaram fazê-lo tomando como base uma perspectiva radicalmente crítica.

Esse traço conservador na profissão pode ser atribuído ao fato de os terapeutas ocupacionais, na busca por um status de cientificidade de sua prática, terem apoiado seu discurso em teorias que priorizam os aspectos técnicos da ação profissional, escamoteando, assim, as determinaçóes que as relaçôes de produçáo engendram na configuração de cada sociedade (MAGALHÁES, 1989). Nesse sentido, Magalhães (1989, p. 15) coloca que:

Durante muito tempo, os terapeutas ocupacionais brasileiros pretenderam construir uma categoria profissional que pudesse, a um só tempo, intervir sobre a realidade concreta da sua clientela sem, contudo, considerar quaisquer contradiçóes entre os interesses das classes componentes dessa mesma sociedade. O resultado dessa pretensa "neutralidade" foi a consolidação de uma categoria profissional plena de lacunas e de ambiguidades.

Percebendo tal situação, alguns profissionais brasileiros iniciaram na década de 1980 um movimento de aproximaçáo da profissão com o referencial teórico marxista e passaram a questionar essa pretensa "neutralidade" profissional, numa direção que visava construir uma Terapia Ocupacional crítica. Desse modo, a literatura profissional brasileira parece ter avançado em relação à estrangeira quando nos referimos aos fundamentos históricos da Terapia Ocupacional numa perspectiva crítica.

Esse avanço decorreu, principalmente, da inserção desses terapeutas ocupacionais em programas de pós-graduação nas humanidades, tendo em vista a inexistência, até recentemente, de programas de pós-graduação específicos da área. Nesse contexto, quando precisamos nos referir a uma análise históricocrítica da Terapia Ocupacional enquanto profissão, merecem destaque as produções de Magalhães (1989), Soares (1991), Lopes (1999) e Medeiros (2003).

O nosso estudo tem como intuito, então, reforçar esse movimento já iniciado por autores da área, no sentido de avançar na pesquisa em Terapia Ocupacional. A particularidade da nossa contribuição talvez resida no fato de retomarmos a gênese e o desenvolvimento da profissáo numa perspectiva ontológica, ou seja, radicalmente crítica, o que requer, necessariamente, adotar o trabalho como categoria fundante do ser social, entendendo, também, as peculiaridades desse na sociedade capitalista, buscando as relaçóes que a profissão mantém com essa categoria e com as outras que emergiram de desdobramentos do trabalho e que, ao longo do desenvolvimento capitalista, mantêm relaçóes com a profissão.
A importância de análises histórico-críticas na profissão está na possibilidade de captar o sentido da prática profissional no processo de reprodução social, ao inserir a Terapia Ocupacional no movimento da sociedade da qual faz parte; de entender os fatores determinantes da gênese e do desenvolvimento profissional, bem como o movimento das demandas colocadas para o terapeuta ocupacional, que requisitam deste profissional competências técnicas, éticas e políticas, a fim de que ele responda, de modo adequado, a essas necessidades; de identificar as contradiçôes presentes nos espaços de atuação profissional e permitir, ao terapeuta ocupacional, um posicionamento crítico ante elas, tendo consciência dos limites sociais objetivos postos à sua intervenção; além de orientar a formação profissional, no sentido de acompanhar as transformaçóes sociais, de caráter micro e macrossocial.

\section{As condições sócio-históricas de emergência da Terapia Ocupacional no capitalismo e sua inserção nas políticas sociais brasileiras}

As investigações realizadas no interior da literatura marxiana e marxista ressaltam a existência de uma íntima relação entre a categoria trabalho e as outras esferas da sociedade. Compreendido enquanto intercâmbio orgânico do homem com a natureza para produzir seus meios de subsistência e instrumentos de trabalho, o trabalho é uma categoria presente em qualquer forma de sociabilidade, e é somente a partir dele que se torna possível a existência do homem e da própria sociedade, enquanto complexo social (MARX; ENGELS, 2009; MARX, 1996). Lukács (1979, p. 17) expóe essa dependência do ser social em relação à natureza afirmando que

[...] o ser social - em seu conjunto, em cada um dos seus processos singulares - pressupóe o ser da natureza inorgânica e orgânica. Não se pode considerar o ser social como independente do ser da natureza.

Sendo assim, o trabalho constitui-se enquanto

[...] base a partir da qual se estrutura qualquer forma de sociabilidade. Não importa qual seja a sua forma concreta; o trabalho, como produtor de valores de uso, será uma necessidade inescapável para a humanidade enquanto ela existir. (TONET; NASCIMENTO, 2009, p. 22). 
Reconhecido esse estatuto ontológico do trabalho enquanto categoria universal do mundo dos homens, é possível entender que foi a complexificação social possibilitada pelo ato de trabalhar ao longo da humanidade que tornou possível o surgimento do Estado e, consequentemente, de diversas profissões, dentre elas a de terapeuta ocupacional, que irão atuar por meio das políticas públicas implementadas por esse Estado para enfrentar as diversas expressôes da chamada questão social.

Desse modo, resultado das formas de organizar a produção em sociedade, mesmo antes do modo de produção capitalista, o Estado emergiu socialmente como um dos mecanismos de dirimir conflitos sociais e manter a dominaçáo de classe, para resguardar a propriedade privada. Analisando a gênese e a natureza do Estado, Engels (1987) afirma que as mudanças nas relaçóes econômicas, em um dado momento da história, fizeram surgir uma nova sociedade, emaranhada em conflitos irreconciliáveis, de classes, que não podiam "[...] subsistir, senão em meio a uma luta aberta e permanente dessas classes entre si, ou sob a dominaçáo de um terceiro poder que, aparentemente [...]", estivesse situado acima dessas classes e "[...] reprimisse esses conflitos abertos e só permitisse que a luta de classes se travasse no campo econômico, numa forma dita legal [...]": o Estado. (ENGELS, 1987, p. 190).

Nesse sentido, o Estado se originou como uma necessidade da sociedade em um momento histórico específico, intimamente articulado com a forma de organizar a produção baseada na propriedade privada. Assim, emergiu como um instrumento da classe dominante para tornar possível a reproduçáo da sociedade a partir do momento em que ela foi dividida em classes com interesses conflitantes e sem possibilidade de serem conciliados.

A partir da estreita relação entre economia e política, Marx compreende o Estado, assim como Engels, como uma expressão das relações econômicas e interesses privados, configurando-se como um instrumento voltado para a garantia das próprias bases, sobre as quais se apoiariam tais relaçôes. Assim, para Marx, o Estado possui uma natureza de classe e jamais pode representar os interesses da sociedade como um todo, haja vista que a sociedade está permeada por interesses de classe antagônicos e irreconciliáveis. Desse modo, o autor expressa, em parceria com Engels, no Manifesto do Partido Comunista, aquilo que poderíamos denominar de concepção marxista sobre o Estado moderno: "um comitê para administrar os negócios coletivos de toda a classe burguesa" (MARX; ENGELS, 1998, p. 7).
Impossibilitado, então, de eliminar por completo os males sociais originários da exploração do trabalho, uma vez que ele só existem como expressão dela ${ }^{3}$, o Estado buscou aperfeiçoar as formas de administrar as desigualdades sociais através de recursos políticos que em nada alteram a sua essência ou que vão ao encontro da lógica reprodutiva. Nesse contexto, a sociedade burguesa provocou uma cisão teórica entre as esferas econômica e política, com o intuito de mistificar essa natureza de classe do Estado e de apresentá-lo como um instrumento acima das classes, capaz de eliminar os males sociais a partir de uma administração pública calcada nos princípios de justiça e eficiência. Visto dessa forma, segundo Holloway (1982), o Estado abstrai os indivíduos das relaçóes capitalistas de produção e toma todos como indivíduos iguais, no plano jurídico-legal: os cidadãos. A cidadania, entáo, é um princípio baseado na existência da desigualdade real, entre os indivíduos, no âmbito da sociedade civil, ou seja, um conceito preso aos limites da ideologia burguesa.

Com essa análise radicalmente crítica sobre o Estado, nota-se que as políticas sociais, enquanto instrumentos estatais de amortização dos conflitos sociais, possuem uma limitação estrutural para resolver os problemas sociais que está atrelada à natureza e à função social do próprio Estado. Assim sendo, pode-se afirmar que, em última instância, tais políticas acabam cumprindo a função de impedir que as desigualdades sociais se agravem a ponto de colocar em xeque a reproduçáo da sociedade capitalista. No entanto, não se trata aqui de ter uma visão fatalista de compreensão de políticas sociais, exclusivamente, como instrumentos de dominação do capital sobre o trabalho, mas de desvelar as possibilidades reais de elas eliminarem a desigualdade social e contribuírem para a luta da classe trabalhadora. Desse modo, ao se constituírem como expressão de interesses opostos, atendendo também a algumas necessidades dos trabalhadores quando esses elevam ao nível da luta política as expressóes da sua exploração, as políticas sociais comportam uma contradição em seu interior.

Apreendendo o trabalho e o Estado nesses moldes, constatamos que a gênese da profissão de terapeuta ocupacional, nos EUA, no início do século $\mathrm{XX}$, apresentou-se como uma expressão da nova modalidade de intervenção do Estado sobre a questão social em um momento específico do desenvolvimento capitalista: o período monopolista. Ao ampliar sua intervenção através de serviços e políticas sociais na idade dos monopólios, o Estado requisitou diversas profissōes para executar tais políticas, dentre elas, a Terapia Ocupacional. 
Assim, a partir da segunda década do século XX, a Terapia Ocupacional se insere na divisão social do trabalho, inicialmente nos EUA, e passa a atender às requisições colocadas por instituições vinculadas ao Estado, contribuindo assim, para a reprodução das relações sociais capitalistas e encontrando a legitimidade de que necessitava para se reproduzir enquanto profissão ${ }^{4}$. Soares (1991, p. 142) afirma que a gênese da profissão decorreu da

[...] necessidade de absorção de parcela do exército de reserva num momento de expansão econômica nos Estados Unidos e das pressóes sociais dos veteranos de guerra por autonomia financeira e valorização social.

Ao se posicionar dessa forma, a autora reforça que a profissão se origina a partir de determinantes econômicos, políticos e sociais, ou seja, se origina como fruto da configuração da relação capital x trabalho, no início do século XX.

Como se observa, nesse contexto coube ao terapeuta ocupacional a função de recuperar a força física de trabalho através de programas de reabilitação profissional destinados aos deficientes e aos portadores de sequelas de guerra necessárias a própria industrialização capitalista. Os programas de reabilitação, fruto também da luta dos trabalhadores, em um contexto de acirramento da luta de classes apresentam em seu interior a contradiçáo inerente às políticas sociais, pois ao mesmo tempo em que preservam a saúde do trabalhador, possibilitam a expansão da economia capitalista através da inserção dele no mercado de trabalho.

Neste estudo sobre a gênese da profissão, focamos nas práticas reabilitadoras e habilitadoras para o trabalho e não nas práticas vinculadas à saúde mental por considerarmos que foi a legitimidade conferida à Terapia Ocupacional através da criação e expansão dos programas de reabilitação profissional pelo Estado monopolista no início do século XX que determinou a sua profissionalização, institucionalização e reprodução nesse momento histórico. Isso não significa negar a importância do atendimento às populaçóes com sofrimento psíquico na história da Terapia Ocupacional, mas sim ir em busca do elemento determinante da inserção da profissão na divisão social do trabalho e que a colocou em outro patamar perante o Estado5.

Desse modo, consideramos que o processo de profissionalização da Terapia Ocupacional guarda relaçôes estreitas com o contexto de expansão da indústria monopolista, influenciada pela gerência científica de Taylor acerca do controle sobre o trabalhador e sua melhor adaptação ao posto de trabalho, bem como com as mudanças realizadas no Estado, quando ele passou a intervir diretamente sobre as expressóes da questão social através de políticas e serviços sociais, com vistas à expansão, à acumulação e o lucro, além do exercício de formas de controle mais consensuais sobre o trabalhador.

Nesse sentido, reafirmamos que a Terapia Ocupacional, ao agir diretamente sobre a reprodução da força de trabalho, cumpre uma funcionalidade na reproduçáo social e encontra condiçôes para sua legitimidade e profissionalização, conquistando um lugar na divisão social do trabalho. É, portanto, com a finalidade da recuperação direta da força de trabalho e de sua inserçáo no mercado de trabalho que a profissão emergiu socialmente, contudo, ao longo do seu desenvolvimento, ela foi incorporando novas atribuições, na medida em que a realidade social colocou novas demandas sociais para o Estado, de acordo com as mudanças no mundo do trabalho.

No contexto brasileiro, a Terapia Ocupacional surgiu quando os programas de reabilitaçáo profissional, de inspiração americana e europeia, foram incorporados às açóes governamentais do período do governo Vargas e institucionalizados no âmbito da previdência social. Também no Brasil, esses programas foram implantados comportando uma contradição, pois atrelada à sua criação estava a constatação de que esses serviços acarretariam não só uma diminuição das despesas públicas com aposentadorias e benefícios por invalidez mas, também, gerariam um aumento da receita se esses inválidos retornassem à condição de segurados ativos, além dos efeitos ideológicos sobre a luta de classes (SOARES, 1991).

É, portanto, nessa lógica que a Terapia Ocupacional é requisitada para compor as equipes multiprofissionais nos programas de reabilitação a fim de contribuir, assim, para a reprodução da força de trabalho e, consequentemente, para a reprodução das relaçôes sociais. Assim, a partir de uma análise crítica sobre as origens da profissão, Soares (1991, p. 196-197) afirma que

[...] a Terapia Ocupacional cumpre, então, funçôes no plano econômico, ao recuperar os incapacitados da porção estagnada do exército de reserva, ampliando a sua porção flutuante que, por seu turno, garante a redução da massa salarial do exército industrial ativo, seja por sua assimilação nos períodos de pico da produção, seja pela rotatividade de mão de obra. [Além disso,] vem corroborar o consumo e capitalização do setor saúde, pela incorporação de equipamentos e materiais industrializados e do próprio cuidado da saúde. 
Em 1956, pela necessidade de formar profissionais em Fisioterapia e Terapia Ocupacional para atuar nas instituições, foi criada a Escola de Reabilitação do Rio de Janeiro, vinculada à Associação Brasileira Beneficente de Reabilitação (ABBR), haja vista a inexistência de cursos de formação para essas áreas no Brasil (SOARES, 1991). De acordo com Magalhães (1989), a abertura dos primeiros cursos de Terapia Ocupacional, no Brasil, deu-se simultaneamente à entrada da indústria de equipamentos médicohospitalares no mercado nacional, como parte do processo de "modernizaçáo" dos quadros técnicos que determinou importantes desdobramentos de caráter econômico. Cabe destacar que o início e a expansão dos cursos de Terapia Ocupacional, no país, deram-se no contexto de avanço da industrialização de um modo geral e não só da indústria de equipamentos médico-hospitalares. Esse fato ocorreu considerando a formação de uma massa operária, principalmente em São Paulo, que iria necessitar de serviços voltados para a recuperação da sua força de trabalho em casos de acidentes como, também, a necessidade de incorporação da parte do exército industrial de reserva, composta pelos deficientes, à medida que o mercado de trabalho no setor se expandia.

No início da década de 1960 houve a expansão de cursos de formação em Terapia Ocupacional no país e em 1963 tem-se a aprovação de um currículo mínimo pelo Conselho Nacional de Educação. No ano de 1964 é fundada a Associação de Terapeutas Ocupacionais do Brasil (Atob), atual Associação Brasileira de Terapeutas Ocupacionais (Abrato), e cinco anos depois, em 13 de outubro de 1969, o Decreto-lei 938 regulamentou a profissão, reconhecendo os terapeutas ocupacionais como profissionais de nível superior. No contexto da primeira metade da década de 1970, os terapeutas ocupacionais uniram-se aos fisioterapeutas e conquistaram, em 1975, através do Decreto-lei n. 6.316, a criação dos Conselhos Federal (Coffito) e Regionais (Crefitos) das categorias, como uma expressão do reconhecimento oficial da profissão ante as políticas de saúde (MAGALHÁES, 1989; SOARES, 1991).

Cabe ressaltar que o momento histórico de consolidação da Terapia Ocupacional no país foi marcado pelo regime da ditadura militar, após o golpe de 1964, no qual houve uma expansáo do poder estatal, visando à garantia da estabilidade social e política, para livre desenvolvimento da economia. Segundo Bravo (2006), a ditadura significou para a totalidade da sociedade brasileira, a afirmaçáo de uma tendência de desenvolvimento econômico, social e político que modelou um novo país. Os grandes problemas estruturais não foram resolvidos mas aprofundados, tornando-se mais complexos e portadores de uma dimensão ampla e dramática.

Nesse período, o enfrentamento da questáo social deu-se através do binômio repressão-assistência, sendo que, nesse momento, a política assistencial foi ampliada, burocratizada e modernizada pela máquina estatal, com o intuito de aumentar o poder de regulação sobre a sociedade, suavizar as tensões sociais e conseguir legitimidade para o regime, como também para servir de mecanismo de acumulação do capital (BRAVO, 2006).

Entendemos, desse modo, que o processo de reconhecimento legal da profissão de terapeuta ocupacional, nesse momento, partiu das necessidades da modernização conservadora do Estado ditatorial, que procurava legitimar-se em áreas críticas, como os serviços de saúde para os trabalhadores e o sistema previdenciário brasileiro, em um momento de crise de legitimidade do regime militar.

Apesar das conquistas na década de 1970, encontramos na literatura profissional o que Soares (1991) denomina de crise de identidade profissional, mas que, no nosso entendimento, corresponde a uma crise das respostas profissionais diante das mudanças no contexto ditatorial e que vem demarcar o início de um possível processo que denominamos de reconfiguração da Terapia Ocupacional no país. Para a autora, nesse período, o Estado passou a requisitar o terapeuta ocupacional para atuar em novas instituiçóes que conflitaram com a base teórica clínica da formação profissional.

Pensamos que tal crise decorreu, portanto, da inadequação das respostas profissionais, até então centradas num modelo clínico, em face das mudanças ocorridas no Estado, que refletiram-se nas instituiçóes onde os terapeutas ocupacionais estavam inseridos ou passaram a se inserir. Nesse contexto, momento de crise de legitimidade da ditadura no país, o Estado buscou ampliar as políticas sociais e a sua intervenção sobre as expressóes da questão social, numa tentativa de recuperar a sua legitimidade perdida. Assim, o Estado passou a incorporar novas demandas sociais, com a ampliação das políticas sociais, o que ocasionou também uma ampliação das requisiçóes profissionais, postas para o terapeuta ocupacional no âmbito institucional. Essas requisições conflitaram com a base teórica que dava sustentação à intervençáo profissional até então, acarretando problemas aos programas de Terapia Ocupacional nessas novas instituiçôes.

Contudo, ressaltamos que a crise das respostas profissionais não se configura como uma crise 
endógena da Terapia Ocupacional, por isso não a denominamos crise de identidade profissional, uma vez que a profissão não perdeu sua legitimidade ante o Estado, pelo contrário, passou a ter seu mercado de trabalho expandido com as novas demandas sociais e com a inserção do terapeuta em novas instituiçóes, como as prisionais e as direcionadas ao menor infrator. Desse modo, pensamos que a crise das respostas profissionais é uma expressáo da própria crise da realidade brasileira, crise do governo autoritário, e vem expressar a relação da Terapia Ocupacional com o Estado e as políticas sociais no contexto da ditadura.

Nesse cenário, além da recuperação da força física de trabalho para atendimento às demandas do acelerado processo de industrialização no país, os profissionais passaram, também, a reforçar suas funçôes de cunho pedagógico em instituiçôes estatais, através de açôes educativas e de prevenção, também em instituiçóes não diretamente ligadas à área da saúde. Assim, as mudanças na profissão nesse período, tanto no exercício profissional quanto na formação, foram medidas para responder funcionalmente às demandas colocadas pela realidade e se adequarem ao modus operandi das instituiçóes sociais e políticas do período da ditadura no Brasil. Vale enfatizar que esse processo possibilitou um avanço profissional, como a aproximação da profissão as ciências humanas, à medida que os profissionais buscaram fazer cursos de pós-graduação em programas das humanidades (principalmente na Sociologia e na Educação), na tentativa de buscar novos subsídios teóricos para analisar e responder às mudanças da realidade. Assim, o contexto da ditadura permitiu, aos profissionais em tela, não só o acúmulo de novos referenciais teóricos mas também a sua inserção em novos espaços institucionais, além da articulação com os movimentos sociais, em especial com aqueles relacionados aos direitos dos deficientes e dos doentes mentais.

Assim, no cenário brasileiro, mantendo relaçóes estreitas com as transformaçóes sociais, a Terapia Ocupacional, ao longo do seu desenvolvimento, foi deixando de ser uma profissão unicamente da reabilitação e incorporou açôes de prevenção de caráter educativo não só na área da saúde, como também em outras políticas públicas. Esse processo que estamos denominando de reconfiguração profissional foi desencadeado na década de 1970, quando novas requisiçóes profissionais decorreram das mudanças, nas políticas sociais brasileiras, como fruto da necessidade de legitimação do Estado brasileiro no contexto da ditadura militar.
Desde entấo, a profissão vem se inserindo em novos campos de atuação e ganhando maior visibilidade, principalmente a partir do processo de redemocratização do país e do envolvimento dos seus profissionais com as lutas sociais. Nessa reconfiguração profissional, o terapeuta ocupacional deixou de ser um profissional exclusivamente da reabilitação física e da saúde mental e garantiu sua inserção em outros programas e políticas da seguridade social, tendo em vista a ampliação dos direitos sociais no país no período pós-constituinte. Essas mudanças podem ser observadas em documentos governamentais, bem como nos documentos do conselho profissional, que vem regulamentando a intervenção do terapeuta nessas novas áreas de atuação ${ }^{6}$.

Esse movimento de incorporaçáo de novas atribuiçóes da profissão, que deixa de ser uma profissão especificamente da reabilitação física ou mental, vem demonstrar que a Terapia Ocupacional está preocupada com a dimensão ocupacional do sujeito não somente na área da saúde, através das políticas de saúde e previdência (reabilitação profissional), mas também em outros campos de ação, onde a saúde deixou de ser o foco principal da intervenção profissional, como a política de assistência social e no campo sociojurídico.

Nesse sentido, acompanhando o movimento das mudanças no mundo do trabalho e nas políticas sociais brasileiras, temos que a profissão veio incorporando novas atribuições e inserindo-se em outros campos de atuação, que não lidam diretamente com a reabilitação física do trabalhador acidentado, ou de pessoas portadoras de deficiências. Isso não significa dizer que ela perdeu a sua relaçáo com a dimensão ocupacional do sujeito, mas sim que ela passou a ser demandada para atuar com populaçóes que não apresentam problemas físicos ou mentais que as impeçam de trabalhar, preocupando-se com sujeitos que, por razóes sociais, encontram-se fora do mercado de trabalho e com problemas de inserção social como, por exemplo, presidiários, pessoas em situação de rua, dentre outros. Desse modo, a ligação da profissão com a saúde do trabalhador ainda permanece na atualidade, mas já não define a especificidade da Terapia Ocupacional.

\section{Considerações finais}

Destacamos, então, que a inserção da Terapia Ocupacional na divisão social do trabalho configura-se como resultado de um processo histórico dependente das formas de intervenção estatal sobre as expressóes da questáo social e, consequentemente, da configuração da luta de classes e da conformação das 
políticas sociais do Estado no contexto do capitalismo monopolista. Nesse sentido, a intervenção profissional apresenta determinantes sócio-históricos, o que significa dizer que a atuação do terapeuta ocupacional é determinada socialmente pelas condiçóes históricas objetivas que dão uma direção social à prática profissional, ultrapassando a vontade subjetiva dos agentes profissionais considerados individualmente.

Analisando o desenvolvimento histórico da Terapia Ocupacional no Brasil, percebemos que ela encontrou e ainda encontra nas instituiçôes públicas estatais seus principais espaços de atuaçáo. Contudo, apesar de o Estado ser o agente histórico que requisitou a profissão, esse mesmo Estado veio assumindo posicionamentos diferentes diante do atendimento às necessidades sociais, abrindo espaço para que o terapeuta ocupacional atue em instituiçôes de outra natureza, de modo que o mercado de trabalho profissional está condicionado às políticas implementadas pelo Estado capitalista.

Contudo, apesar da expansão do mercado de trabalho profissional, devido à maior inserção da Terapia Ocupacional nas políticas da seguridade social, com o apoio do Estado, o que se presencia na contemporaneidade é um contexto contraditório de expansão das demandas sociais, devido às condiçóes adversas do mundo do trabalho e da desresponsabilização do Estado, tendo em vista a implantação das políticas de cunho neoliberal no país. Essa realidade tem posto novos desafios éticos, políticos, teóricos e práticos para a profissão, de modo que cabe ao terapeuta definir os limites para a intervenção e saber fazer uso da sua autonomia relativa, percebendo as contradiçôes institucionais para que, na sua ação, possa ultrapassar as requisiçóes profissionais direcionadas a ele pela instituição e atender às verdadeiras necessidades dos sujeitos-alvo de sua intervenção.

Para tanto, é necessário que o terapeuta ocupacional tenha clareza de que a sua ação profissional está ligada ao processo histórico da realidade, já que a Terapia Ocupacional emerge e se desenvolve na sociedade capitalista para atender às necessidades antagônicas (capital x trabalho) dessa sociedade. Por isto, as possibilidades da profissão estấo condicionadas aos limites do sistema capitalista, mas podem estar mais próximas, ou mais distantes do projeto social dos trabalhadores, dependendo da orientação dada pelo profissional à sua intervenção junto a esses sujeitos.

Desse modo, buscamos analisar a Terapia Ocupacional em sua totalidade, enquanto uma prática social em processo e que se modifica de acordo com o modo como se expressam as contradiçóes próprias da sociedade capitalista, pois à medida que as necessidades sociais modificam-se, a profissão é obrigada a redefinir-se para responder às novas demandas e requisiçôes que lhe são colocadas no contexto de reconhecimento das demandas sociais e institucionais. Assim, o estudo revelou alguns dos possíveis fios (in)visíveis que ligam a Terapia Ocupacional às mudanças implementadas pelo capital na organização do trabalho, no âmbito do Estado e das políticas sociais.

\section{Referências}

BEZERRA, W. C. A Terapia Ocupacional na sociedade capitalista e sua inserçâo profissional nas politicas sociais no Brasil. 2011. 163 f. Dissertação (Mestrado em Serviço Social)-Universidade Federal de Alagoas, Maceió, 2011. BRAVO, M. I. S. Política de Saúde no Brasil. In: MOTA, A. E. et al. (Org.). Serviço Social e Saúde: formação e trabalho profissional. São Paulo: Cortez, ABESS, Ministério da Saúde, OPAS, OMS; 2006. p. 88-109.

ENGELS, F. A origem da Família, da Propriedade Privada e do Estado. 11. ed. Rio de Janeiro: Civilização Brasileira, 1987.

HOLLOWAY, J. Fundamentos Teoricos para una Crítica Marxista de la Administración Pública. México: Instituto Nacional de Administração Pública, 1982.

LARA, R. Pesquisa e Serviço Social: da concepção burguesa de ciências sociais à perspectiva ontológica. Revista Katálysis, Florianópolis, v. 10, p. 73-82, 2007. Número especial. http://dx.doi.org/10.1590/S1414-49802007000300008 LIMA, T. C. S.; MIOTO, R. C. T. Procedimentos metodológicos na construção do conhecimento científico: a pesquisa bibliográfica. Revista Katálysis, Florianópolis, v. 10, p. 37-45, 2007. Número especial. http://dx.doi. org/10.1590/S1414-49802007000300004

LOPES, R. E. Cidadania, politicas públicas e Terapia Ocupacional, no contexto das açóes de saúde mental e saúde da pessoa portadora de deficiência no município de São Paulo. 1999. 548 f. Tese (Doutorado em Educação)Universidade Estadual de Campinas, Campinas, 1999.

LUKÁCS, G. Ontologia do Ser Social: os princípios ontológicos fundamentais de Marx. Tradução de Carlos Nelson Coutinho. São Paulo: Livraria Editora Ciências Humanas, 1979.

MAGALHÃES, L. V. Os terapeutas ocupacionais no Brasil: sob o signo da contradição. 1989. 157 f. Dissertação (Mestrado em Educação)-Universidade Estadual de Campinas, Campinas, 1989.

MARX, K. Contribuição à crítica da economia política. Tradução de Maria Helena Barreiro Alves. São Paulo: Martins Fontes, 1983.

MARX, K. O Capital: crítica da economia política. Tradução de Régis Barbosa e Flávio R. Kothe. São Paulo: Nova Cultural, 1996. v. 1, tomo 1. (Coleção Os Economistas). 
MARX, K; ENGELS, F. A Ideologia Alemã. São Paulo: Expressão Popular, 2009.

MARX, K. Glosas Criticas Marginais ao Artigo "O rei da Prússia e a Reforma Social" de um Prussiano. Sáo Paulo: Expressão Popular, 2010.

MARX, K.; ENGELS, F. Manifesto do Partido Comunista. 2. ed. São Paulo: Cortez, 1998.

MEDEIROS, M. H. R. Terapia Ocupacional: um enfoque epistemológico e social. São Paulo: Editora Hucitec, EdUFSCar, 2003.

MONTAÑO, C. A natureza do Serviço Social. São Paulo: Cortez, 2007.
NETTO, J. P. Capitalismo monopolista e Serviço Social. 7. ed. São Paulo: Cortez, 2009.

SÁ-SILVA, J. R.; ALMEIDA, C. D.; GUINDANI, F. F. Pesquisa documental: pistas teóricas e metodológicas. Revista Brasileira de História \& Ciências Sociais, São Leopoldo, v. 1, n. 1, p. 1-15, 2009.

SOARES, L. B. T. Terapia Ocupacional: lógica do capital ou do trabalho?. São Paulo: Editora Hucitec, 1991.

TONET, I.; NASCIMENTO, A. Descaminhos da Esquerda: da centralidade do trabalho à centralidade da política. São Paulo: Editora Alfa-Omega, 2009.

\section{Contribuição dos Autores}

Waldez Cavalcante Bezerra: organização e análise das fontes documentais e bibliográficas; concepção, redação e revisão do texto manuscrito. Rosa Lúcia Prédes Trindade: orientação e revisão do texto.

\section{Notas}

${ }^{1}$ As reflexôes aqui apresentadas fazem parte da dissertação de mestrado A Terapia Ocupacional na sociedade capitalista e sua inserçáo profissional nas políticas sociais no Brasil apresentada por Waldez Cavalcante Bezerra em setembro de 2011 ao Programa de Pós-graduação em Serviço Social da UFAL, sob a orientação da Profa. Dra. Rosa Prédes.

${ }^{2}$ Neste artigo citaremos apenas os principais autores da Terapia Ocupacional que subsidiaram a nossa reflexão, mas muitos outros que fizeram análises históricas da profissão também foram utilizados e reconhecemos as devidas contribuiçôes.

${ }^{3}$ Marx desenvolve tal concepção extensivamente em um artigo publicado no periódico Avante! (Vorwärts!), em 1844, intitulado Glosas críticas marginais ao artigo "O rei da Prússia e a reforma social" de um prussiano, onde procura evidenciar os equívocos de buscar-se a raiz da ineficiência da ação do Estado para a soluçáo dos problemas sociais (MARX, 2010).

${ }^{4}$ Concordamos com Montaño (2007, p. 47) quando afirma que o "que dota de legitimidade uma profissão é basicamente o fato de certas necessidades sociais serem reconhecidas, transformadas em demandas e respondidas por determinadas instituiçôes e organizaçôes, as quais empregam os profissionais para estudar e/ou intervir nessas realidades". Nesse sentido, o Estado, ao se preocupar com as questôes de saúde do trabalhador, para conter o movimento operário e atender aos interesses do capital, mostrou-se historicamente o principal empregador dos terapeutas ocupacionais e possibilitou a legitimação da profissão.

${ }^{5}$ Em nossa dissertação exploramos o papel das práticas que utilizavam a atividade na área da psiquiatria (tratamento moral, ergoterapia e laborterapia) e que influenciaram a Terapia Ocupacional, contudo buscamos compreender tais práticas e sua relação com a profissão a partir do conceito de protoformas, desenvolvido por Netto (2009). Tal abordagem nos permitiu identificar as linhas de continuidade e ruptura entre essas práticas e a Terapia Ocupacional, constatando-se que elas não foram o fator determinante para o surgimento da profissão e nem da sua inserção na divisão social do trabalho. Devido aos limites impostos pela estrutura de um artigo, não poderemos explorar essa discussão devido à sua complexidade e extensão. O leitor interessado pode consultar Bezerra (2011) para aprofundamento.

${ }^{6}$ Podemos citar: no âmbito da formação, a Resolução CNE/CES 6/2002 (atuais Diretrizes Curriculares Nacionais do Curso de Graduação em Terapia Ocupacional) (BRASIL, 2002); no âmbito da Previdência, o Projeto de Revitalização da Reabilitação Profissional de 2008; na área da saúde, a Lei n. 10.216/2001 (que dispóe sobre a proteção e os direitos das pessoas portadoras de transtornos mentais e redireciona o modelo assistencial em saúde mental) (BRASIL, 2001), a Portaria n. 336/GM de 2002 (que dispóe sobre os Centros de Apoio Psicossocial) (BRASIL, 2002) e a Portaria n. 154/2008 (que cria os Núcleos de Apoio a Saúde da Família) (BRASIL, 2008); no campo sociojurídico, a Portaria n. 287/2010 (BRASIL, 2010) do Departamento Penitenciário Nacional (Depen) e o Sistema Nacional de Atendimento Socioeducativo (Sinase); no âmbito da assistência social, a Resoluçáo n. 383/2010 do Coffito (que regulamenta a intervenção do terapeuta ocupacional no Sistema Único de Assistência Social - SUAS) (COFFITO, 2010) e a Resolução n. 17 do Conselho Nacional de Assistência Social - CNAS (que reconheceu as categorias profissionais de nível superior que devem atender às especificidades dos serviços socioassistenciais, bem como das funções essenciais de gestão do SUAS) (BRASIL, 2011). 